\title{
Influence of the dominant thinking style in the degree of novelty of designs in virtual and traditional working environments
}

Elena Mulet1*, Vicent Chulvi1, Marta Royo1, Julia Galán2

1 Department of Mechanical Engineering and Construction, Universitat Jaume I, Castellón, Spain

2 Department of Industrial Systems Engineering and Design, Universitat Jaume I, Castellón, Spain

* Corresponding author: Elena Mulet, Department of Mechanical Engineering and Construction, Universitat Jaume I.

Postal address: Avda Sos Baynat s/n 12071. Castellón, Spain.

E-mail: emulet@emc.uji.es Telephone: +34 9647281 17 Fax: +34 964728106

Author: Vicent Chulvi

Postal address: Avda Sos Baynat s/n 12071. Department of Mechanical Engineering and Construction, Universitat Jaume I. Castellón, Spain.

E-mail: chulvi@emc.uji.es Telephone: +34 964728113 Fax: +34 964728106

Author: Marta Royo

Postal address: Avda Sos Baynat s/n 12071. Department of Mechanical Engineering and Construction, Universitat Jaume I. Castellón, Spain.

E-mail: royo@emc.uji.es Telephone: +34964729491 Fax: +34 964728106

Author: Julia Galán

Postal address: Avda Sos Baynat s/n 12071. Department of Industrial Systems Engineering and Design, Universitat Jaume I. Castellón, Spain.

E-mail: galan@esid.uji.es Telephone: +34 964728202 Fax: +34 964728170 


\title{
Influence of the dominant thinking style in the degree of novelty of designs in virtual and traditional working environments
}

\begin{abstract}
One's thinking and reasoning style defines individual preferences when interacting and communicating with others. This work aims to analyse whether the thinking and reasoning style of the design teams exerts an influence on the degree of novelty of the design outcomes in two working environments: a faceto-face environment and a virtual environment. To address this, an experiment was set up in which 21 teams, each made up of three design students, were asked to obtain new solutions to two design problems, one of them in a face-to-face environment and the other in a virtual environment. The teams were defined according to their thinking and reasoning style, and the novelty of the design outcomes was measured with the SAPPhIRE model of causality. The results show that, overall, the degree of novelty is very similar in both environments, although it is a little higher in virtual environments. Teams with a rational style produce more novel results when using ICT than in a face-to-face environment. Teams with an interpersonal style, on the other hand, generate the least novel solutions when using technologies and produce the most novel solutions when they work in a face-to-face environment.
\end{abstract}

Keywords: thinking styles, collaborative design, design novelty, creativity

\section{Introduction}

Creativity and team work are key issues in the design and development of new products in general, and more so during the conceptual phase. Several studies have investigated this (Stempfle and Badke-Schaub 2002; Berger et al. 2014). Designers usually need to work in teams to collaborate but teams cannot always be located in the same place, in which case they are known as distributed or virtual design teams. It is in this virtual collaborative context where information and communication technologies (ICT) play an important role in enabling designers to communicate with each other (Simoff and Maher 2000), and several tools are available to make this possible (Amitani, Bilda and 
Edmonds 2008; Leggte and Bilda 2008). Audio-visual and online resources such as webcams, video conference, chat and shareable files applications are common, accessible and quite familiar to many design professionals.

Conceptual design is a crucial phase in the design process and creative problemsolving is a key task during this phase, which is mainly supported by expression through writing and sketching. Visual and verbal expressions are more than a means of communication - they are an intrinsic part of the design process and are involved in creativity, as highlighted by Purcell and Gero (1998) and Suwa, Purcell and Gero (1998). Several authors have researched into the importance of visual expression in the generation of ideas in design groups (Van der Lugt 2000; Yang 2009). So, when designing in virtual environments, design teams share verbalizations and sketches to support creativity. Some researchers claim that it is feasible for future computer-aided design systems to be expanded in order to support a design process carried out on an interactive basis with the designer (Candy and Edmonds 2000), and the need to research what kinds of activities are adequate for working in virtual teams is highlighted in MacGregor and Torres-Coronas (2007).

It is usually accepted that face-to-face communication is easier but it could be interesting to know whether, during the conceptual design process, there are persons who feel more comfortable and express themselves better using virtual communication. Tang et al. compared design teams in traditional and digital environments when generating creative solutions (Tang, Lee and Gero 2011). In their study, the digital environment tries to emulate the traditional one, so the designers worked together in a synchronous mode using audio-visual communication. Functionality and innovation were two of the parameters used to compare the outcomes of the two environments. 
Conclusions suggest that the design process shows no significant differences regardless of whether it is undertaken in pen and paper or digital drawing environments.

The collaborative capabilities depend on different aspects, such as the level of expertise (Kleinsmann et al. 2011), and they have been studied to analyse knowledge integration and the approaches to solving the design problem in teams (Yang, Dong and Helander 2011).

The personal thinking and reasoning style may also influence the knowledge sharing capabilities. Different classifications have been put forward for the individual thinking style. Recent studies show that neuroimaging measurements do not reveal any differences in the use of brain zones as a global property (Nielsen et al. 2013). Nonetheless, there are previous classifications of the thinking style that still refer to parts of the brain, thus identifying thinking styles with particular brain zones. Examples of such proposals include the left and right hemisphere model (Sperry, Gazzaniga and Bogen 1969), the classification into limbic and cortical brains (MacLean and Kral 1973), or the Herrmann whole brain model (Herrmann 1991). Those thinking style classifications are based on modes of thinking rather than on parts of the brain even though reference is made to such parts. Neuroscience focuses its research on revealing the way in which a part of the brain is used. Thus, in the literature reviewed the parts of the brain are mentioned as a metaphor. Other classifications point directly to the thinking style, such as Guilford's classification between convergent and divergent reasoning (Guilford 1980) or the classification between adaptive and innovative individuals (Kirton 1976), among others.

The relation between the thinking style and the design outcomes has been analysed for face-to-face teams (López-Mesa et al. 2005; López-Mesa and Thompson 2006; Dayan and Di Benedetto 2011). In the work by López-Mesa et al. the degree of 
novelty of adaptive and innovative design teams is compared by means of Kirton's test (Kirton 1985, 1992, 1999). The results show that innovative groups generate solutions that are more novel at a functional level, whereas adaptive groups generate more novel solutions at a structural level. This result confirms that the designer's problem-solving style - adaptor or innovator - has to be considered in the selection of design methods (López-Mesa and Thompson 2006). Another study analysed the relation between the eight personal creativity modes of Wilde (1999), which combine extroverted and introverted modes with intuitive, sensing, thinking and feeling modes and the design activities in eight designers. In this case, results showed that different creative modes lead to the designers' focusing on different design activities and, in particular, feelingoriented personal cognitive characteristics are related to a greater use of external knowledge and more unique designs (Kim, Jin and Lee 2009). In Dayan and Di Benedetto (2011), the degree of creativity of the product obtained by rational, intuitive and mixed groups is measured and compared, and it is found that groups with long experience generate more creative products when they combine intuitive and rational thinking. In low-experienced groups, in contrast, it is rational thoughts that lead to more creative results.

The influence of personality factors on the outcomes of design teams has been analysed in several studies. For instance, the Gough's personality factors (Gough and Heilbrun 1983) of 78 teams made up of students were identified and compared to the outcomes of a design project (Freiheit 2015). The results show that some personality attributes are important and explain a significant percentage of the design outcome score. The influence between personal creative modes according to Wilde's (Wilde 1999) classification and design outcomes creativity scored using a CPSS scale (Besemer and O'Quin 1999) has been studied in two teams conducting a conceptual design task. 
The results showed that both teams obtained similar results in the novelty category and the team with diverse personality performed better in the useful category (Kim, Kim and Wilde 2008). Agreeable personality, linked to gentle and cooperative people, is positively related to design team outcomes (Peeters et al. 2008).

The research conducted to date on design teams provides evidence that personality and thinking style has an influence on the design outcomes. More studies are needed in order to assess the effect of the interactions between personality factors (Freiheit 2015) and the interactions with other factors, such as the environment or the type of design problem. Studies have therefore been conducted on the notion that the designers' thinking style influences the design outcomes, especially for lowexperienced designers.

A deeper understanding of the influence of the communication environment in relation to the thinking style would allow potential problems to be prevented, leading to improved performance of distributed teams during creative design.

In addition, technology is becoming more and more present in our lives. People are used to communicating and sharing ideas and contents with others through ICT. CACD (Computer Aided Conceptual Design) tools are becoming more popular despite their resolution and quality limitations in comparison to pen-and-paper sketching. This can lead sketching-based virtual environments to make differences in the design outcomes.

The aim of this work is to identify, by means of an experimental project, the influence of the dominant thinking style in the design team outcomes in two types of environment: a face-to-face environment and virtually, this latter involving the use of ICT to communicate with each other within the team. The purpose of this work is to analyse whether, depending on the personal thinking style, the teams produce less novel 
results in a distributed working environment that does not allow for all the communication channels between the team members. Hence, the research questions are:

- Do teams working in a face-to-face or a distributed environment generate solutions with different levels of novelty?

- Does the level of novelty change in each environment depending on personal thinking style of the team?

\section{Research methodology}

\subsection{Herrmann whole brain model}

The Herrmann's Brain Dominances Test (Herrmann 1991; 1996) is a tool for measuring and describing people's preferences or thinking styles developed by Herrmann in 1979 and validated by Bunderson (1980). It should be noted that this tool does not seek to assess the level of intelligence, but instead to determine the thinking style qualitatively, so there is no "good" or "bad" profile.

In his model of thinking dominances, Herrmann identifies four different thinking modes (Figure 1): analytical (A), sequential (B), interpersonal (C) and imaginative (D). According to the dominant thinking style, people undertake actions in different ways and their communication preferences and their team working are also different. Analytical people (A) are characterized by logical and analytical reasoning and they prefer to clarify and explain; sequential people (B) prefer sequential thinking, they like to plan and perform structured and detailed work; interpersonal people (C) are characterized by an interpersonal thinking style, they prefer to talk and express their ideas to other people and are affectively involved in their tasks, and lastly the imaginative (D) are more original and holistic people who usually work with metaphors and concepts (Figure 1). 
In order to determine the brain dominance, a test with 120 items is applied (Herrmann 1989). The result of the test is a value for each of the four areas (A, B, C, D), in such a way that the values obtained for those questions determine which the dominant area is and thus the cognitive preference of the person. According to the dominance, it is possible to know which brain profile is the most responsible and which are the characteristics of the person's interaction with both the environment and other individuals.

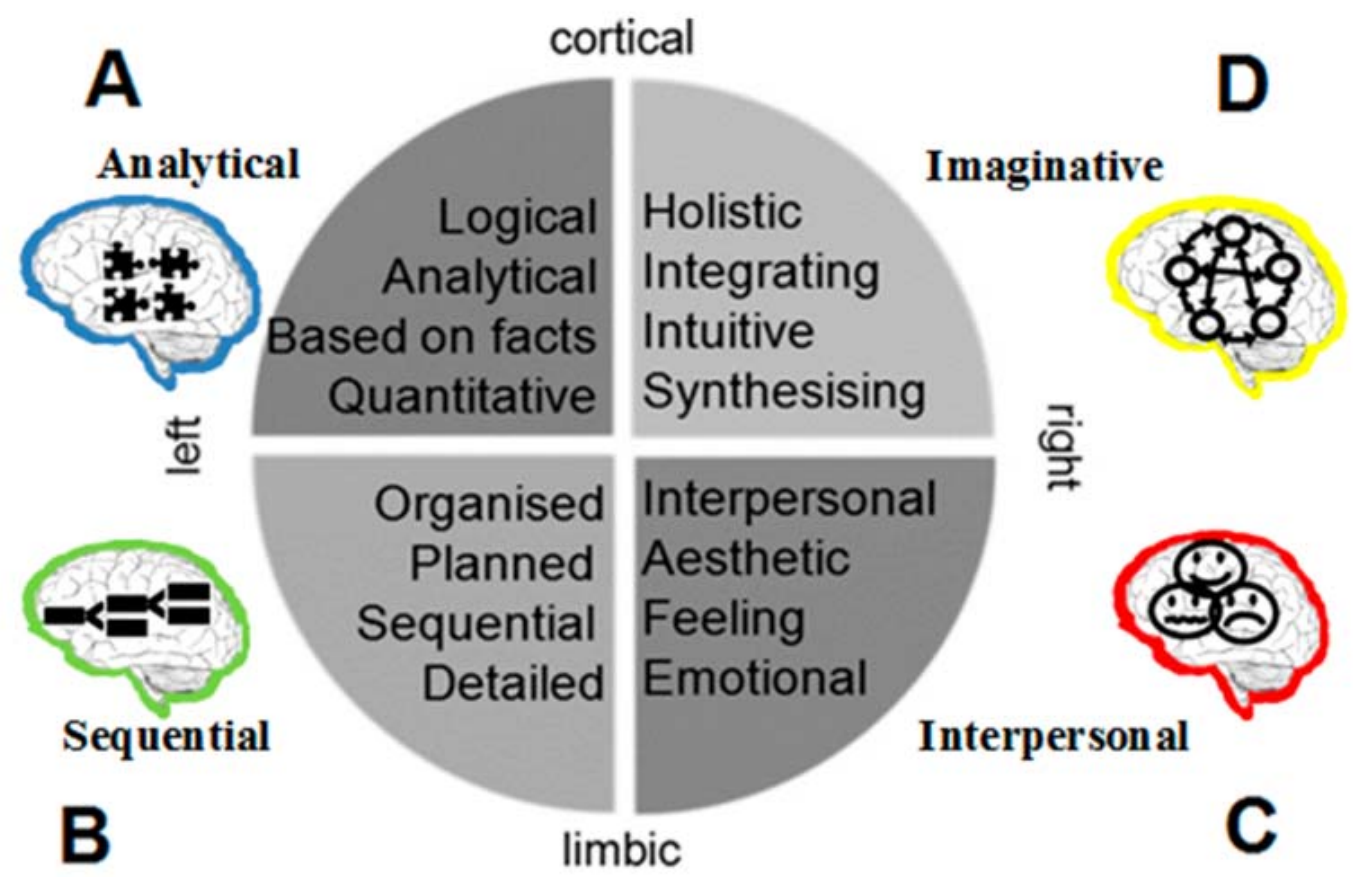

Figure 1. Herrmann's thinking model dominances

It is also possible to detect more than one dominance (simple dominance), such as a double dominance or a triple or even a quadruple or total dominance.

For this work the simplified test by Jiménez-Vélez (2003) based on the Herrmann questionnaire is used. This test is composed of 40 items instead of 120 and it is also suitable for identifying the preference style during thinking in a quicker and easier way than with Hermann's original questionnaire. Even though absolute values are not obtained with this simplified questionnaire, it is possible to distinguish the relative 
thinking style preference, according to the relative scores of the questions related to each of the four categories, which is enough for the aims of the present study.

\subsection{Research Experiment}

An experiment was performed with students in their last year of a Bachelor in Engineering in Industrial Design degree course. A total of 63 students participated (24 male and 39 female). The students knew each other for over three academic years, so they have previously interacted and developed trust.

Prior to the experiment, the students were asked to answer the Jiménez-Vélez questionnaire to assess their thinking style dominance. The answers were analysed and the students were classified according to their thinking style, forming 21 teams of 3 students, with 2 teams of rationalists-analyticals (A), 5 of sequential people (B), 4 of interpersonal people (C), 4 of imaginatives (D), and 6 teams in which each member presented a different dominance, which were called mixed teams (M). The number of design teams for each thinking style is different due to the fact that the thinking style brin of design students is not balanced, as there were a lot of students with profile B and only a few with profile A. In fact, several studies have analysed the profile distribution according to the type of study, (Chulvi et al. 2013; Royo et al. 2014) among others.

Each design group was required to solve two conceptual design problems, one of the problems in a face-to-face environment and the other problem in a virtual environment using ICT. They were given no indications about which design method they could use, in order to prevent a particular design method from producing better results in one of the two environments, which is not the aim of this research. The design problems used in the experiment consisted in designing new household devices that could be used to perform an action that was usually done manually: 
(1) Problem 1: to design a domestic device for painting fingernails.

(2) Problem 2: to design a domestic device for taking the fishbone out of small and medium-sized fish.

The nature of the design problems may also influence the results. Therefore, the characteristics of these design problems are studied considering the influencing variables. The level of expertise in relation to these problems is novice (Dreyfus 2003), cited in (Dorst 2004). Other relevant variables from taxonomies of design problems (Frost 1994) were studied. The complexity of both design problems are similar and the level of innovation according to Frost (1994) is high. Although the two problems are similar in terms of these variables, the participants are more familiar with painting nails than with removing the fishbone of fish. Consequently, the results for each problem will be compared to check whether the difference in how much they are concerned with each problem influences the results.

For the face-to-face environment, design teams were located in a room equipped with a table and sketching material, such as DIN A3 and DIN A4 sized sheets of paper, pencils, crayons and erasers. In a corner of the room, a video camera was installed to record the design process during the experiment, so that there was a register of the data for later analyses of the design process. On the other hand, for the virtual task, each member was located in a separate room provided with a laptop connected to the network and with flexible tablets and electronic pencils, which allow the user to sketch and visualize the drawing on the screen in real time. The software used for collaborative sketching is that provided by Google Drive, which was chosen because it is easy to use and has an intuitive interface which allows for quick learning. In addition, its similarity with the Windows Paint application, known by most of the subjects in this experiment, led us to expect that they could already be familiarized with many of the functions and 
characteristics of the Google Drive tool for sketching. The tool provides a working space that is very similar to the one used in the face-to-face work, which allows the use of similar drawing resources (type and thickness of lines, colours, text) and also a chat application to help participants communicate with each other. The chat allows textual or written interaction but audio-visual interaction is not available, since the purpose of this study is to analyse the level of novelty of the outcomes in two situations with different channels of interaction.

With the aim of recording all the design process in the virtual session, a screencast application was used to capture the evolution of the work in each computer. These resources provide both visual (sketches) and written communication, which help support the designers in different ways during distributed design collaboration (Alahuhta and Vartiainen 2014).

\subsection{Experiment description}

The experiment was performed in one and a half days, since the number of teams that could be doing the experiment at the same time was limited to four, and so series of twelve students were called at each round of the experiment. The experiment was performed in three stages. The first one is the preparation, in which the 12 students were taught about the tools they were going to use during the experiment and had the chance to practise with them for around 30 minutes prior to the experiment. In the second phase, students were divided into teams of three and located in rooms: two teams started working face-to-face and two teams started working separately. The experiment session lasted 50 minutes, divided into a problem-understanding stage ( 5 minutes), followed by a problem-solving stage. Ten minutes from the end of the session, a facilitator asked the team to make sure that they had selected and sketched the final design. In the third phase of the experiment, design teams were asked to solve the design problem that had 
not been assigned to them in the previous phase, working in the environment that had not been used before (Figure 2).
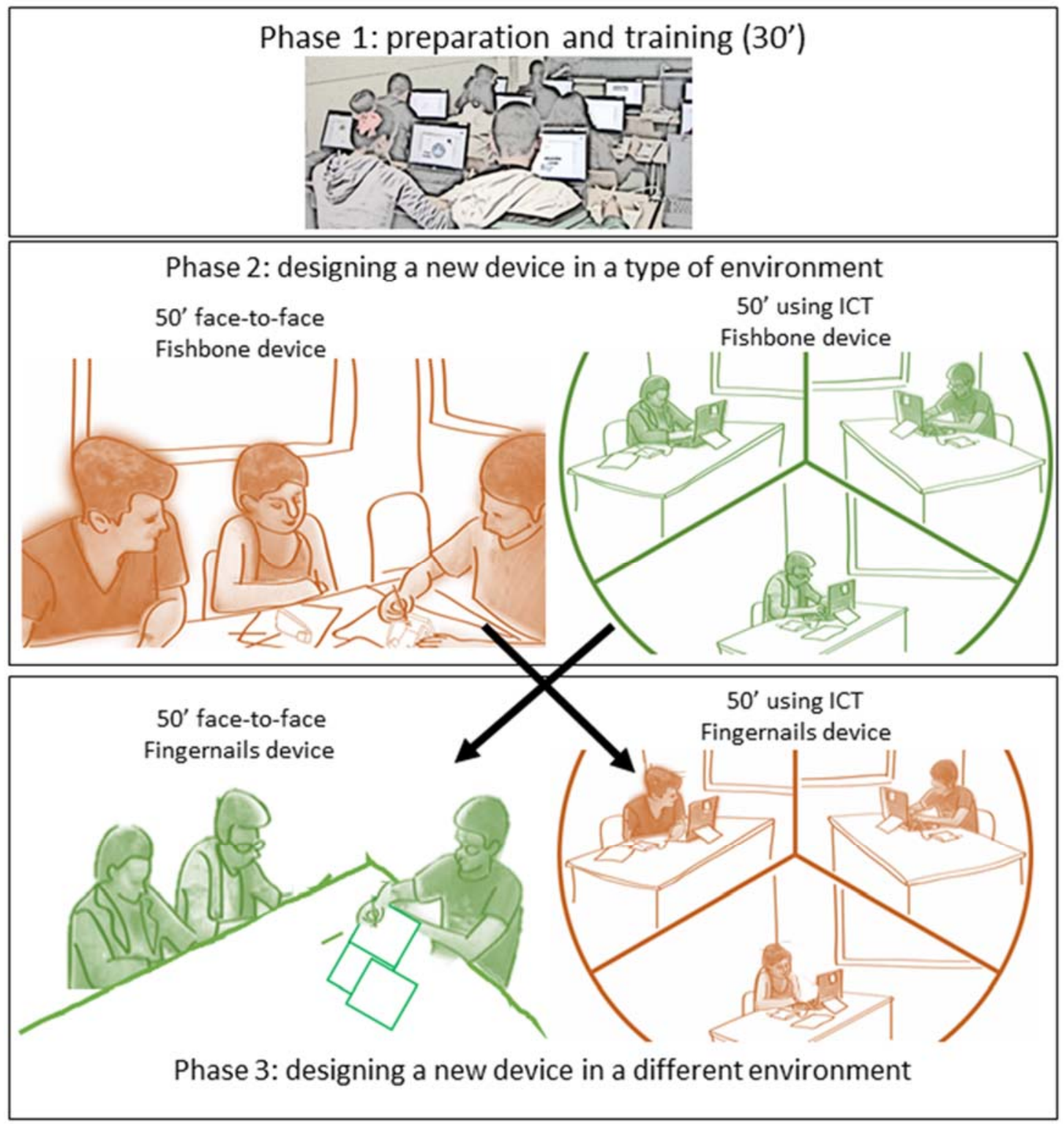

Figure 2. Experiment phases

\subsection{Novelty measurement}

To measure the degree of novelty, the SAPPhIRE-based method proposed by Sarkar and Chakrabarti is used (Sarkar and Chakrabarti 2011). This method compares the characteristics of a product with the previous ones, where the product characteristics are modelled by means of the causality of the functionality, to assess the relative degree of 
novelty of the products. This model is composed of the following constructs (Chakrabarti et al. 2005):

(1) Phenomenon: interaction between the system and its environment.

(2) State change: change in a property of the system (and environment) that is involved in the interaction.

(3) Effect: principle that governs interaction.

(4) Action: abstract description or high-level interpretation of interaction.

(5) Input: physical quantity (material, energy or information) that comes from outside the system boundary, and is essential for interaction. It is needed to activate a physical effect.

(6) Organs: properties and conditions of a system and environment required for interaction.

(7) Parts: physical elements and interfaces that constitute a system and interaction with the environment.

These constructs are related to the Function-Behaviour-Structure (FBS) modelling of products (Gero 1990; Umeda et al. 1990), where action could be taken as function, parts as structure and the rest stand for the behaviour. There are three relationships among these constructs: activation, creation and interpretation. Parts are necessary for creating organs, whereas organs and inputs are needed for activating physical effects, which allow the creation of physical phenomena and changes of state. Finally, changes of state are interpreted as actions or inputs, and can create or activate parts.

The degree of novelty is assigned depending on the level at which the difference between a design solution and a standard one is identified. As can be seen in Figure 3, action is the abstract description or interpretation of a higher-level change of state or 
input creation. Thus, a change at this level represents the highest novelty. If the changes consist in a change of state and input, the novelty is high.

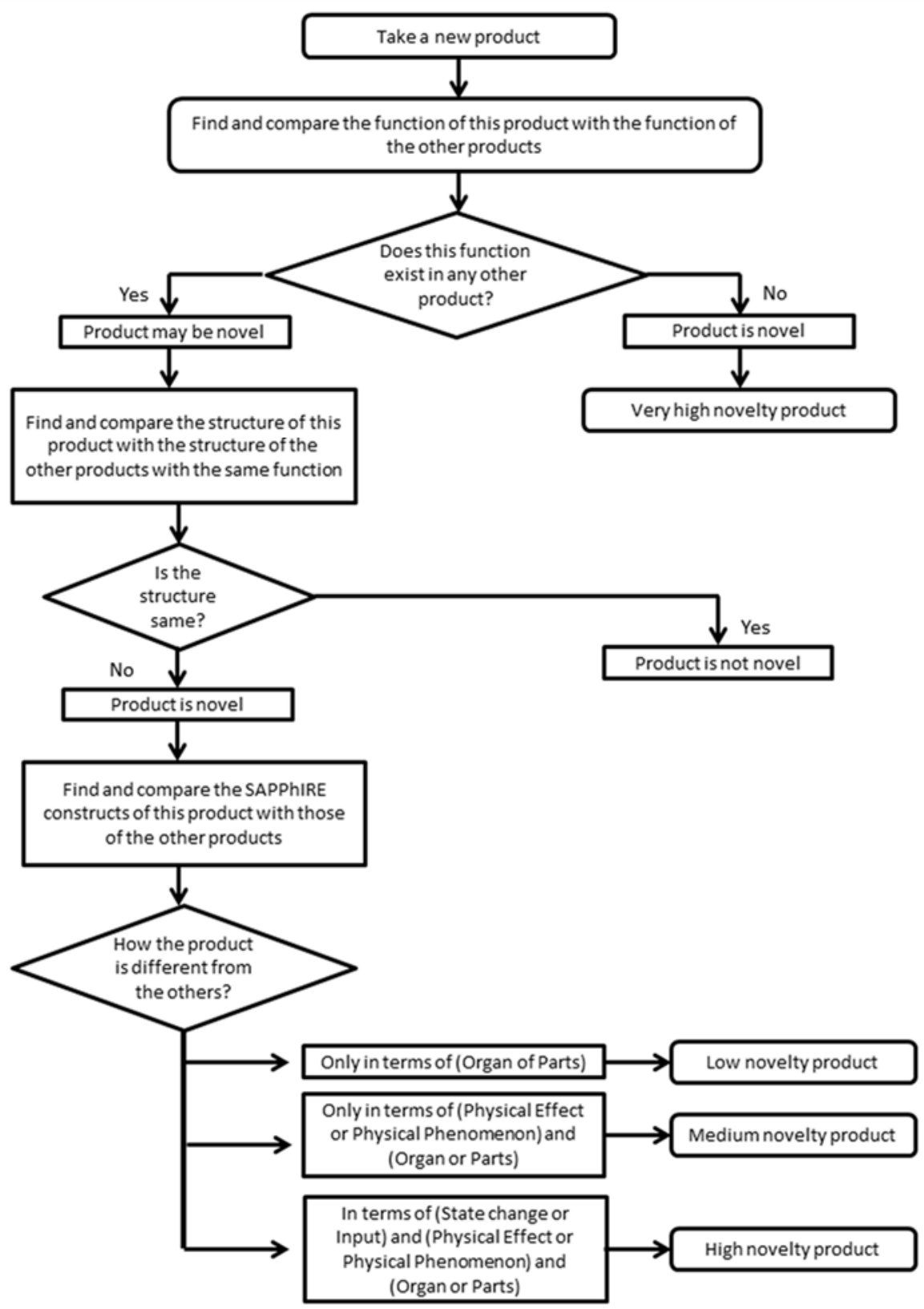

Figure 3. Steps for assessing the novelty (Sarkar and Chakrabarti 2011)

At a medium level of novelty, there are physical phenomena and physical effects. While physical phenomena comprise the potential changes related to a physical phenomenon for a defined set of inputs and organs, physical effects are defined by the 
nature laws that rule those changes. The lowest level of novelty is presented when the design only changes in its organs or parts.

Moreover, this metric presents other advantages, since it is correlated to the variety of the concept space during idea generation, that is to say, the higher the novelty is, the higher the variety of the solutions explored will be, which is another metric to measure the creative ideation process (Shah and Vargas-Hernández 2003).

Novelty measured by this process is related to design process parameters such as the variety of the concept space during idea generation (Srinivasan and Chakrabarti 2010).

\section{Results}

As a result, 21 designs for a device for painting fingernails and 21 designs for a device for removing the fishbone from fish are obtained in the experiment, 21 outcomes being generated in virtual teams and 21 in face-to-face teams. Figures 4, 5, 6, 7 and 8 show some of the design outcomes for each team profile: analyticals (A), sequentials (B), interpersonal (C), imaginatives (D) and mixed (M). The hand-sketched designs were digitalized in order to make them undistinguishable from the digitally sketched ones, thereby ensuring a more objective evaluation.

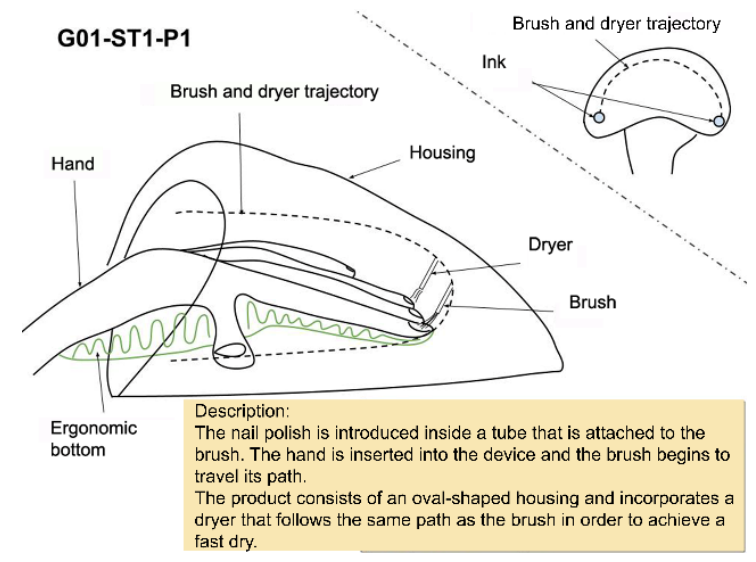

G01-CT2-P2
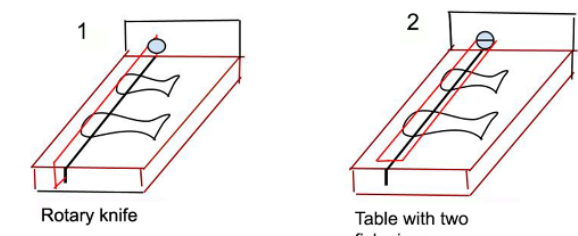

Table with two
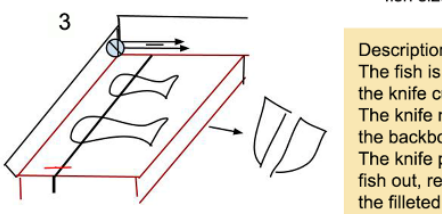

The fish is placed in the hole and the knife cuts the head off. The knife makes two cuts and removes the backbone from the sides. The knife pushes the parts of the fish out, removing the backbone and the filleted parts. 
Figure 4. Examples of design solutions from profile A teams

\section{G06-ST1-P1}

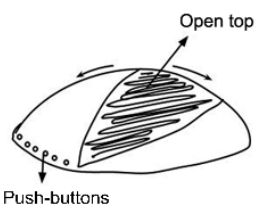

Push-buttons
Hemispherical box.

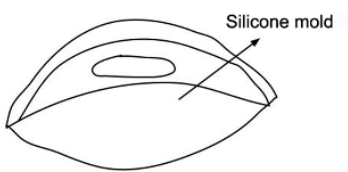

Description: Take the lid off and put your hand in. 3 D scanner recognizes the nails and a brush paints only the area of the nails.

Features: single-dose nail polish cartridges, nail polish remover box to the clean the brush, and both French manicure and standard styles are possible.
G06-CT2-P2
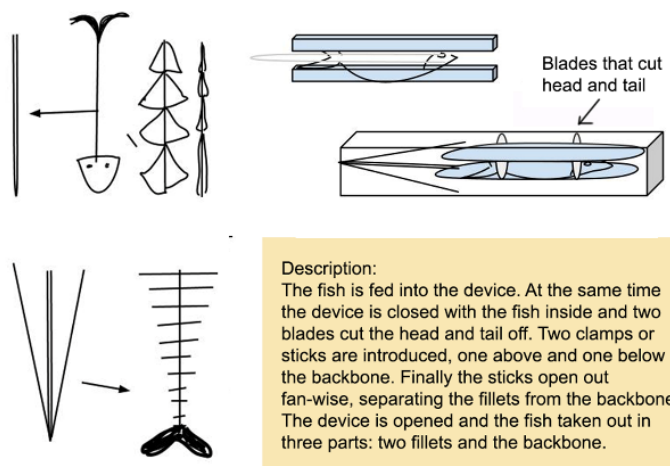

Description

The fish is fed into the device. At the same time the device is closed with the fish inside and two blades cut the head and tail off. Two clamps or sticks are introduced, one above and one below the backbone. Finally the sticks open out

fan-wise, separating the fillets from the backbon the device is opened and the fish taken out in

Figure 5. Examples of design solutions from profile B teams

\section{G07-CT1-P1}

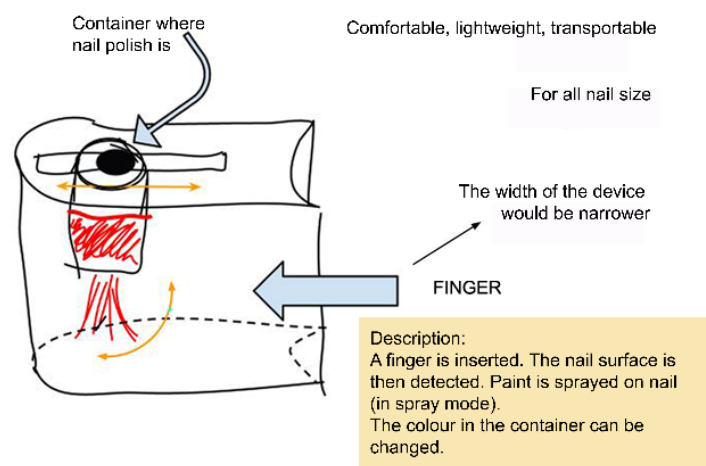

G07-ST2-P2

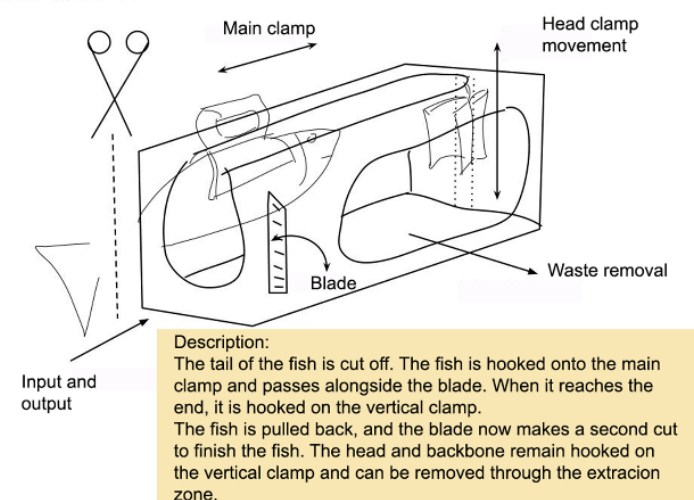

Figure 6. Examples of design solutions from profile $\mathrm{C}$ teams

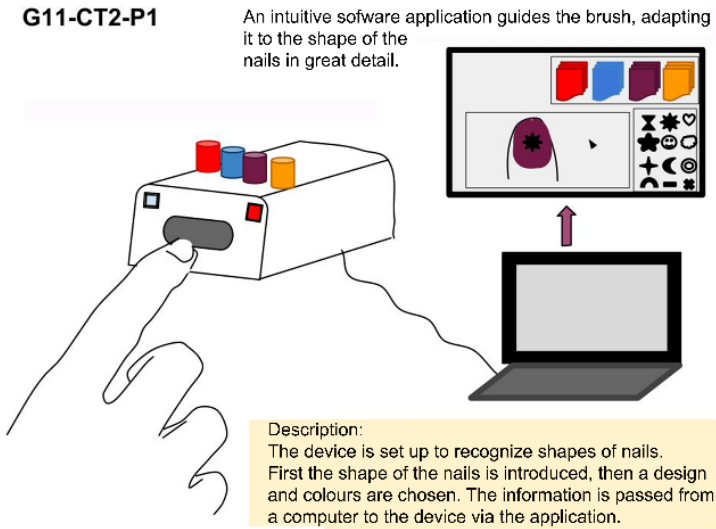

G11-ST1-P2

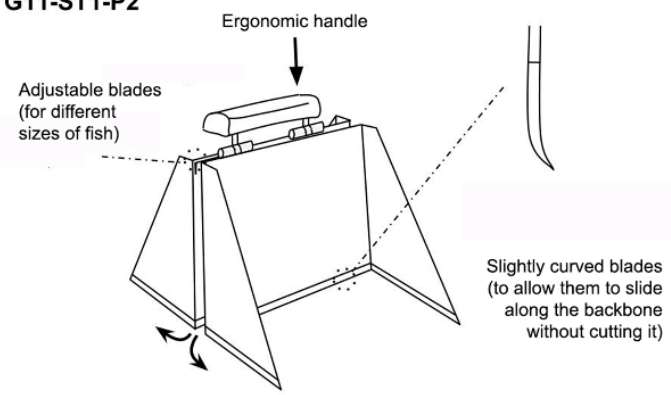

Description:

The fish is placed flat on the surface and the device is positioned above it. A force is applied to the fillet the fish with the lower blade, which when pressure is applied to the handle, causes the blades to slide to the sides (see arrows in the drawing), thus separating the waste from the fillets. 
Figure 7. Examples of design solutions from profile D teams

G17-CT2-P1

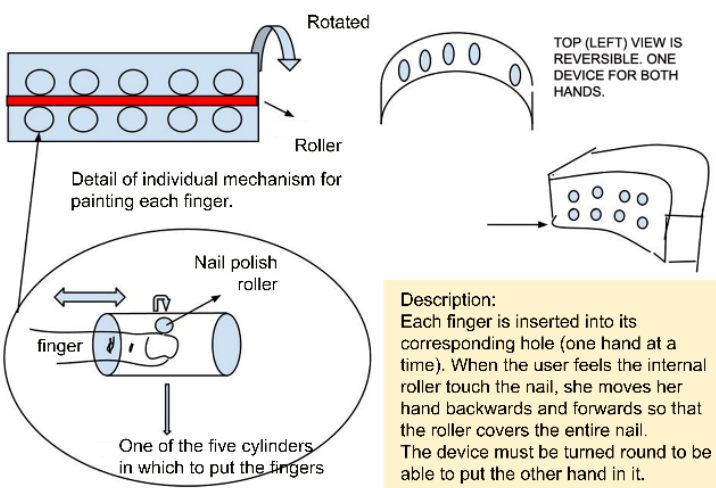

G17-ST1-P2

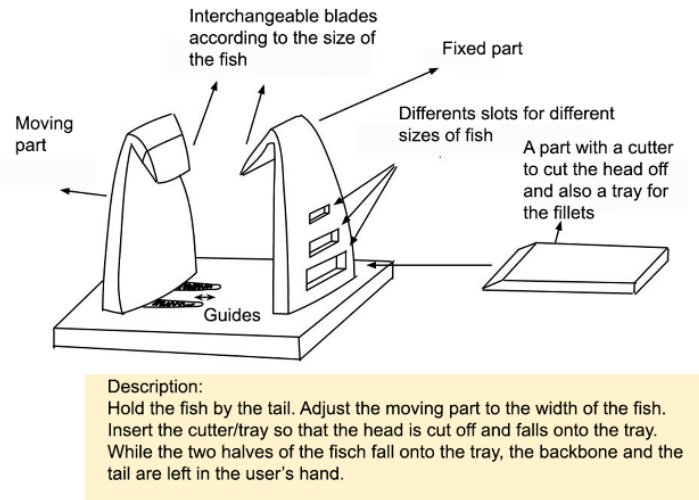

Figure 8. Examples of design solutions from mixed $\mathrm{M}$ teams

3.1. Analysis of the novelty of the design outcomes

The degree of novelty of all the design outcomes ( 21 for the fingernail painter and 21 for the fishbone remover) was evaluated following the method depicted in Figure 3. First of all, the action, state change, physical phenomena, physical effects, organs, parts and inputs for the abstraction of a standard solution were defined for each design problem. Then, the SAPPhIRE constructs were defined for all the design outcomes, after analysing the sketches and the textual descriptions of the solutions provided by the teams. Then, a comparison between each design outcome and the standard solution was performed at each level, which yielded three possible results: the solution is equal to the standard solution; it is better, which is marked with a positive $(+)$ sign; or it is worse, which is marked with a negative sign (-). If there is more than one feature that improves or gets worse, it is evaluated with the positive or negative sign and the number of changes. For example, if one design outcome provides two parts better than those defined in the standard solution, then the "Parts" level is evaluated as +2 . Thus, if the standard solution for the fingernail painter device proposes that there have to be several deposits or one deposit with several compartments for different colours, a solution with just one deposit for one colour is a negative change from the 
standard solution, whereas adding a channel which allows the colours to be mixed to generate new colours is considered a positive change.

Two different evaluators or coders had a high percentage of coincidences on identifying changes in any of the SAPPhIRE constructs. The initial observed agreement between the two coders was 0.89 , and the Cohen's Kappa index was 0.79 , which is a substantial agreement according to the index interpretation (Landis and Koch 1977). All the SAPPhIRE constructs with a disagreement were identified and discussed. This discussion helped clarify the coders' particular interpretations until a consensus was reached. Table 1 shows the standard solutions for the two design problems. Standard solutions are defined and used as a baseline with which compare how better or worse other solutions are in comparison to that baseline. Although a sketch of the standard solution is included in Table 1, defining a set of parts in the SAPPhIRE construct does not define a single physical configuration of the standard solution. Thus, several variants of the standard solution could be depicted for each one by changing, for instance, the position of the colour deposits or the grappling hook.

An example of the comparison between the standard solution and the design shown in Figure 9 is presented in Table 2. Here it can be seen that at a higher level of novelty, "Action", there is no change, since the main function of the device is the same: painting nails. The first change in terms of novelty comes at the "State change" level, since the nail polish is in spray form instead of being a viscous liquid. Physical phenomena and effect remain unchanged. The next level with changes is at the "Organ" level, where an organ to spray the polish has been added, but the solution does not present an organ for colour selection (which is present in the standard solution), so the novelty change at this level is $+1-1=0$. Lastly, at the "Part" level, the solution lacks the 
deposit that is present in the standard solution, but it has two new parts, the nail sensor

and the air dryer, so the result at this level is a value of 1 .

Table 1. Standard solution defined to compare the design outcomes

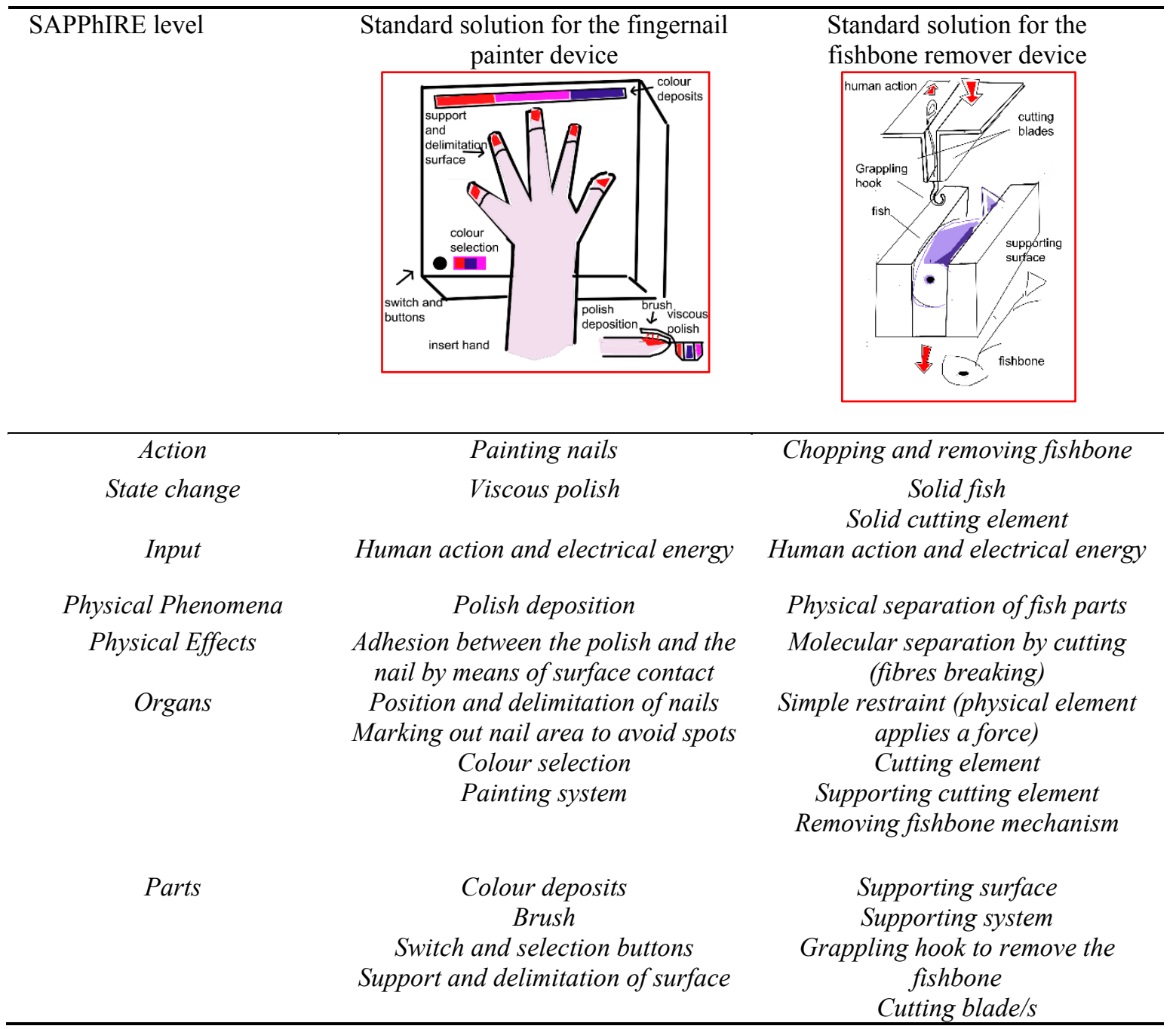

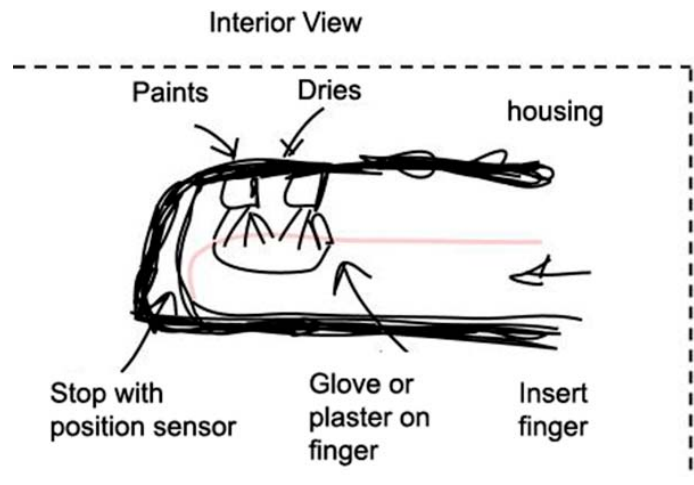

Description:

1) The user covers his hand with a glove exposing the nails or covering the skin with tape

2) The user introduces her hand in the device

3)The device detects the fingers and the nails position. Once it detects that the fingers are correctly positioned, it paints the nails with a sprayer (this spray can be easily removed from the skin)

4)The device dries the painted nails with a hot air blast 5)The user draws back the hand and cleans the remaining nail polish adhered to the skin 
Figure 9. Example of design outcome

Table 2. SAPPhIRE comparison of the design depicted in Figure 7 with the standard solution

\begin{tabular}{|c|c|c|c|}
\hline SAPPhIRE level & $\begin{array}{c}\text { Standard solution for the fingernail } \\
\text { painter device }\end{array}$ & $\begin{array}{l}\text { Comparison with } \\
\text { the standard }\end{array}$ & $\begin{array}{l}\text { Number resulting } \\
\text { from the comparison }\end{array}$ \\
\hline Action & Painting nails & $=$ & 0 \\
\hline State change & Viscous polish & + Spray & 1 \\
\hline Input & Human action and electrical energy & $=$ & 0 \\
\hline Physical Phenomena & Polish deposition & $=$ & 0 \\
\hline Physical Effects & $\begin{array}{l}\text { Adhesion between the polish and the } \\
\text { nail by means of surface contact }\end{array}$ & $=$ & 0 \\
\hline Organs & $\begin{array}{c}\text { Position and delimitation of nails } \\
\text { Marking out nail area to avoid spots } \\
\text { Colour selection } \\
\text { Painting system }\end{array}$ & $\begin{array}{c}\quad= \\
\quad= \\
+ \\
+ \text { Spray }\end{array}$ & 0 \\
\hline Parts & $\begin{array}{c}\text { Colour deposits } \\
\text { Brush } \\
\text { Switch and buttons } \\
\text { Support and delimitation surface }\end{array}$ & $\begin{array}{l}\text { - One deposit } \\
\quad= \\
= \\
+ \text { Nail sensor } \\
+ \text { Air dryer }\end{array}$ & 1 \\
\hline
\end{tabular}

When the comparison is finished, the number of improvements (positive items) and the number of negative items are quantified for each level of abstraction. Once this has been performed for all the solutions, a rank of novelty is assigned to each one, in such a way that the solution with the most positive changes on the more abstract level (State change) is the most novel one; if there is more than one solution with the same improvements at the "State change" level, then the one with more improvements at the "Physical effects" level is the most novel; if more than one solution present the same positive changes at this level, then the next level is compared, and so on. In this way, the evaluation of the degree of novelty is related to the number of positive changes (a better solution than the standard one) and negative changes (a worse solution than the standard one). So, as can be deduced in Table 3, the design represented in Figure 9 is more novel than the standard solution. 
The result of the evaluation is shown in Tables 3 and 4, where only the

SAPPhIRE levels where there has been a change in at least one solution are represented.

That is, since the physical phenomenon is the same for all the solutions, it is not included in these tables. The last column shows the ranking position of the degree of novelty for the solutions being evaluated.

Table 3. Novelty evaluation rank for the nail painter device solutions

\begin{tabular}{|c|c|c|c|c|c|c|c|c|c|}
\hline $\begin{array}{l}\text { Thinking } \\
\text { style }\end{array}$ & Group & Technology & $\begin{array}{c}\text { State } \\
\text { change }\end{array}$ & Inputs & $\begin{array}{c}\text { Physical } \\
\text { effect }\end{array}$ & Organs & Parts & Rank & $\begin{array}{c}\text { More or less } \\
\text { novel than the } \\
\text { standard } \\
\text { solution }\end{array}$ \\
\hline$A$ & 1 & No ICT & 0 & 0 & 0 & -1 & 2 & 14 & Less \\
\hline$A$ & 2 & No ICT & 0 & 0 & 0 & 0 & 4 & 8 & More \\
\hline$B$ & 6 & No ICT & 0 & 0 & 0 & 0 & 3 & 9 & More \\
\hline$B$ & 10 & No ICT & 0 & 0 & 0 & 0 & 2 & 11 & More \\
\hline$B$ & 16 & No ICT & 0 & 0 & 0 & -1 & 0 & 18 & Less \\
\hline$C$ & 5 & No ICT & 0 & 0 & 0 & 1 & 3 & 6 & More \\
\hline$C$ & 19 & No ICT & 0 & 0 & 0 & -1 & 2 & 14 & Less \\
\hline$D$ & 3 & No ICT & 0 & 0 & 0 & -1 & -1 & 21 & Less \\
\hline$D$ & 12 & No ICT & 0 & 0 & 0 & -1 & 1 & 17 & Less \\
\hline Mixed & 13 & No ICT & 0 & 0 & 0 & 1 & 3 & 6 & More \\
\hline$B$ & 8 & $I C T$ & 1 & 0 & 0 & -1 & -1 & 4 & More \\
\hline$B$ & 20 & $I C T$ & 0 & 0 & 0 & 0 & 3 & 9 & More \\
\hline$C$ & 7 & $I C T$ & 1 & 0 & 0 & 0 & -1 & 3 & More \\
\hline$C$ & 9 & $I C T$ & 0 & 0 & 0 & 0 & 0 & 13 & Equal \\
\hline$D$ & 11 & $I C T$ & 0 & 0 & 0 & 0 & 2 & 11 & More \\
\hline$D$ & 15 & $I C T$ & 0 & 0 & 1 & 1 & 1 & 5 & More \\
\hline Mixed & 4 & $I C T$ & 0 & 0 & -1 & 0 & -1 & 20 & Less \\
\hline Mixed & 14 & $I C T$ & 1 & 1 & 0 & 0 & 0 & 2 & More \\
\hline Mixed & 17 & $I C T$ & 0 & 0 & 0 & -1 & 0 & 18 & Less \\
\hline Mixed & 18 & $I C T$ & 0 & 0 & 0 & -1 & 2 & 14 & Less \\
\hline Mixed & 21 & $I C T$ & 1 & 1 & 0 & 0 & 2 & 1 & More \\
\hline
\end{tabular}

Table 4. Novelty evaluation rank for the fishbone remover device solutions

\begin{tabular}{|c|c|c|c|c|c|c|c|c|c|}
\hline $\begin{array}{l}\text { Thinking } \\
\text { style }\end{array}$ & Group & Technology & $\begin{array}{c}\text { State } \\
\text { change }\end{array}$ & Inputs & $\begin{array}{c}\text { Physical } \\
\text { effect }\end{array}$ & Organs & Parts & Rank & $\begin{array}{c}\text { More or less } \\
\text { novel than the } \\
\text { standard } \\
\text { solution }\end{array}$ \\
\hline$B$ & 8 & No ICT & 0 & 0 & 0 & 0 & 0 & 7 & Equal \\
\hline$B$ & 20 & No ICT & 0 & -1 & 0 & 0 & -1 & 18 & Less \\
\hline$C$ & 7 & No ICT & 0 & -1 & 0 & 0 & 2 & 5 & More \\
\hline$C$ & 9 & No ICT & 0 & 0 & 0 & 0 & 2 & 4 & More \\
\hline$D$ & 11 & No ICT & 0 & -1 & 0 & 0 & 0 & 13 & Less \\
\hline$D$ & 15 & No ICT & 0 & -1 & 0 & 1 & 0 & 2 & More \\
\hline Mixed & 4 & No ICT & 0 & -1 & 0 & 0 & 3 & 3 & More \\
\hline Mixed & 14 & No ICT & 0 & -1 & 0 & 0 & -2 & 21 & Less \\
\hline
\end{tabular}




$\begin{array}{cccccccccc}\text { Mixed } & 17 & \text { No ICT } & 0 & -1 & 0 & 0 & -1 & 18 & \text { Less } \\ \text { Mixed } & 18 & \text { No ICT } & 0 & -1 & 0 & 0 & -1 & 18 & \text { Less } \\ \text { Mixed } & 21 & \text { No ICT } & 0 & 0 & 0 & 0 & 1 & 6 & \text { More } \\ A & 1 & I C T & 0 & 0 & 0 & 0 & 0 & 7 & \text { Equal } \\ A & 2 & I C T & 0 & 0 & 0 & 1 & 0 & 1 & \text { More } \\ B & 6 & I C T & 0 & 0 & 0 & 0 & 0 & 7 & \text { Equal } \\ B & 10 & I C T & 0 & 0 & 0 & 0 & 0 & 7 & \text { Equal } \\ B & 16 & I C T & 0 & 0 & 0 & 0 & 0 & 7 & \text { Equal } \\ C & 5 & I C T & 0 & 0 & 0 & 0 & -1 & 16 & \text { Less } \\ C & 19 & I C T & 0 & -1 & 0 & 0 & 0 & 13 & \text { Less } \\ D & 3 & I C T & 0 & 0 & 0 & 0 & 0 & 7 & \text { Equal } \\ D & 12 & I C T & 0 & -1 & 0 & 0 & 0 & 13 & \text { Less } \\ \text { Mixed } & 13 & I C T & 0 & 0 & 0 & 0 & -1 & 16 & \text { Less }\end{array}$

\subsection{Comparison of the novelty rank in both environments}

The ranking is also represented graphically in Figure 10, which has a horizontal axis and a vertical axis. The vertical axis divides the figure into two parts: the left side shows the novelty rank of the experimental cases in which the teams worked with face-to-face communication and the right side represents the novelty of the design outcomes generated when the teams worked using ICT. The horizontal axis represents the degree of novelty of the standard solution (SS) in such a way that from this axis to the upper part of the figure those designs which are more novel than the SS are represented, whereas those solutions that are less novel than the SS are represented below the horizontal axis. The greater the distance between the solution and the horizontal axis is, the more/less novel the solution is. The figure is divided into vertical sections, which represent the level of the SAPPhIRE model in which the change between the solution and the SS is identified (part, organ, physical effect, physical phenomena, state change and action). The design outcomes represented on the horizontal axis are equal to the SS in terms of novelty. In this figure it can be observed that, overall, the degree of novelty is quite similar in both environments, although it is a little more novel when ICT are employed. The people participating in this experiment belong to the digital age and are familiar with technologies and virtual environments. This could be a reason why this environment does not seem to inhibit the creative process. 
It seems that the fingernail problem is more motivating since more novel solutions were obtained for it. In fact, the top five novel solutions were obtained using ICT and for the fingernail problem. For the fishbone device all the solutions are more similar to each other in terms of the degree of novelty and many of the changes correspond to the "Parts" and "Organ" levels. As regards the type of environment, Figure 10 shows that in the ICT environment the differences between the degrees of novelty of the results are higher than when no ICT are used.

It can be observed that in the fingernail painter device problem there were more changes in the degree of novelty. The most positive change was at the "State change" level, which was obtained in four of the solutions. In contrast, there is one design outcome that presents a worsening at the "Physical effect" level in comparison to the standard solution.

In the design of a device to remove the fishbone, the solutions present moderate novelty changes. The most novel solution in this problem arises from a change at the "Organs" level, whereas the least novel solutions present worse features at the "Parts" level. Hence it can be deduced that the type of problem did have some influence and the creative process was not equal, which could be due to the fact that the participants in the experiment had different levels of experience and different motivations, since the participants were last-year students on the Bachelor of Industrial Design degree course, and more than $60 \%$ of them were females. It can therefore be assumed that most of the participants had previous experience in painting nails and could be more motivated to think about new solutions, whereas it is likely that few of them had faced the problem of how to clean a fish at home. Informal conversations with students conducted at the end of the experiment confirmed that the motivation was different for the two problems, being lower for the problem related to filleting fish. 


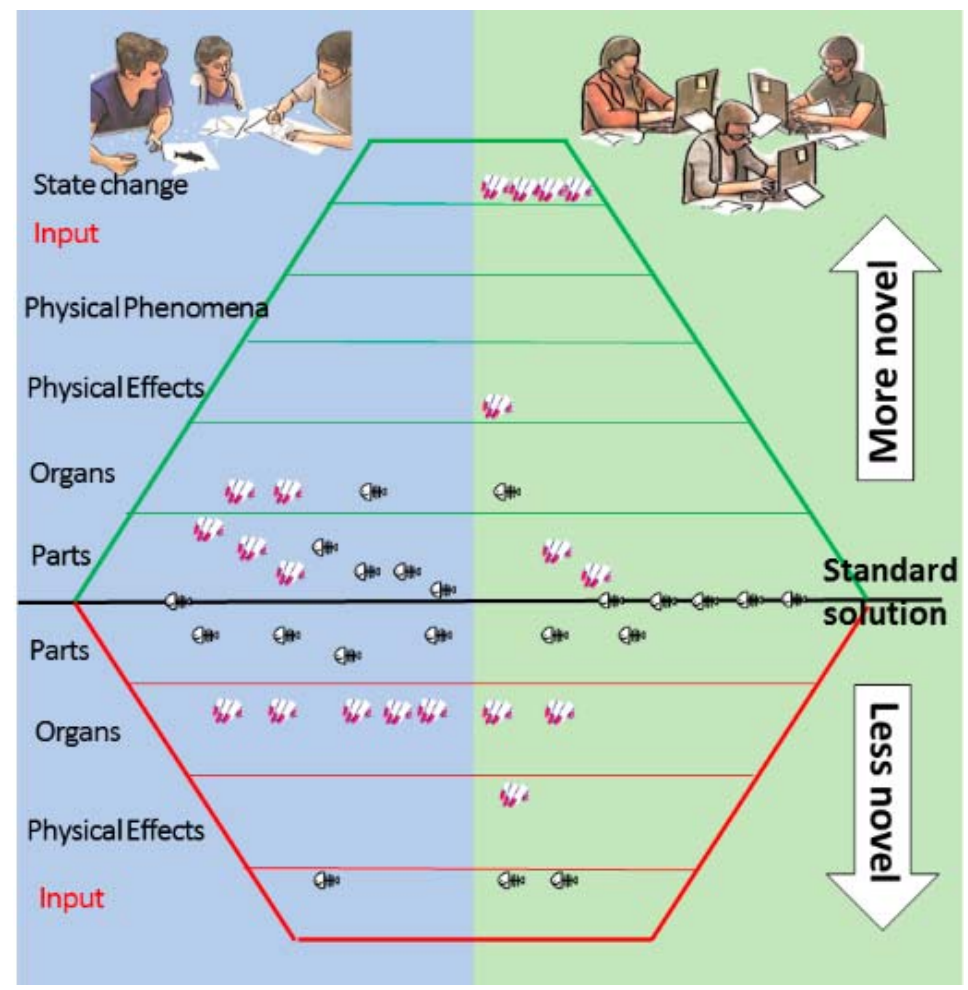

Figure 10. Novelty rank of the design outcomes for the two design problems and the two environments

It can also be observed that using ICT leads to changes in the degree of novelty at higher levels of the SAPPhIRE model, although this only happens with the fingernail painter problem. Looking at the degree of novelty of the solutions obtained for this problem, it can be seen that when the teams use ICT to communicate with each other, the degree of novelty is higher (novelty at the State change level), whereas when they are working in a face-to-face environment the changes in the level of novelty only reach the "Organs" level. In the fishbone remover device, the highest level of novelty is the same in both types of environments, but there are a higher number of solutions with low level improvements when the teams worked in a face-to-face environment.

From the results obtained there seems to be a relationship between the kind of problem and how much the design problem motivates the designers, and the type of environment: virtual or traditional. In a face-to-face environment there is no big 
difference in the level of novelty depending on how much the design problem motivates the designers, yet, if ICT are used, the novelty is more sensitive to how much the design problem motivates the designers.

The sum of the ordinals obtained in the novelty ranking is found for the solutions generated in face-to-face groups and for the solutions obtained in the virtual groups. Since the most novel solutions have the first positions (first, second, third, etc.), the lower the sum is, the more novel the solutions are. From Figure 11, which shows this sum graphically, it can be deduced that in both design problems, the solutions are more novel when ICT were used, but the difference is not very big.

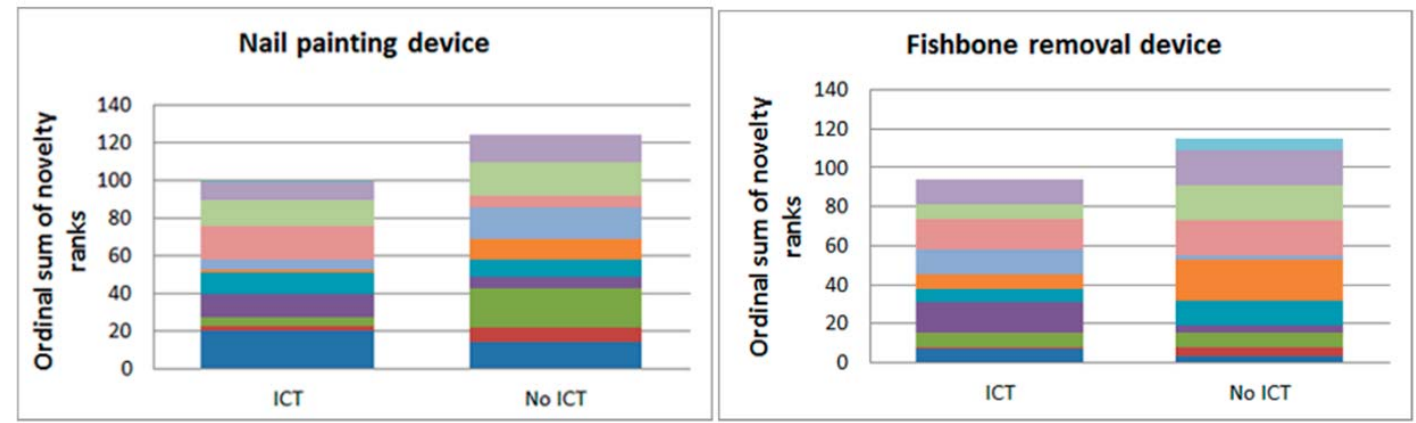

Figure 11. Ordinal sum for the degree of novelty according to the type of environment: with information and communication technologies (ICT) and without information and communication technologies (No ICT)

A Chi-Square test was applied to the frequency of design outcomes that are less, equally or more novel than the standard solution in both environments, as shown in the contingency table (Table 5), the null hypothesis $\mathrm{H} 0$ being that the environment and the qualitative degree of novelty are independent.

Table 5. Contingency table of the degree of novelty in each design environment

\begin{tabular}{lccc} 
& Less novel & Equally novel & More novel \\
\hline No ICT & 10 & 1 & 10 \\
ICT & 7 & 6 & 8
\end{tabular}


The result is that $X^{2}=4.323>X^{2}$ critic $=5.991$, with 2 degrees of freedom and a significance value of $p=0.115$. Therefore, the null hypothesis is not rejected with the available data and so it cannot be proved that the environment influences the qualitative novelty of the design outcomes.

A Student's T test of paired samples is then conducted to check where there is a correlation between the novelty rank of a design team and the environment used. To do this, the first step is to check whether the data follow a normal distribution or not. Since the sample size is lower than 30, a Shapiro-Wilks test was carried out on the data, the result being that that they can be considered to follow a normal distribution. The T test is then applied, considering the null hypothesis to be that the novelty rank obtained by a design team does not depend on the environment. The following are the results $(t=-1.159$, dof $=20, p=0.260)$, and the value of the bilateral statistic $t$ for 20 degrees of freedom and $\alpha=0.05$ is $t_{\text {crit }}=2.080$. Hence, the null hypothesis cannot be rejected and with the available data the two environments generate no statistical differences in the level of novelty. The Wilcoxon test was also performed and again the results showed that no differences can be proved between the novelties of the design outcomes generated in the two environments.

Thus, it cannot be determined whether the choice of a virtual or a face-to-face environment influences creativity.

\subsection{Comparison of the novelty rank according to the thinking style and the environment}

Figure 12 shows the novelty rank according to the thinking style. As has been mentioned above, the number of cases is different for each thinking style: two teams with A (logical-analytical) dominance, five teams with an organizational B profile, four with profile $\mathrm{C}$ (humanitarians), four with a $\mathrm{D}$ (holistic) profile and six mixed teams. 


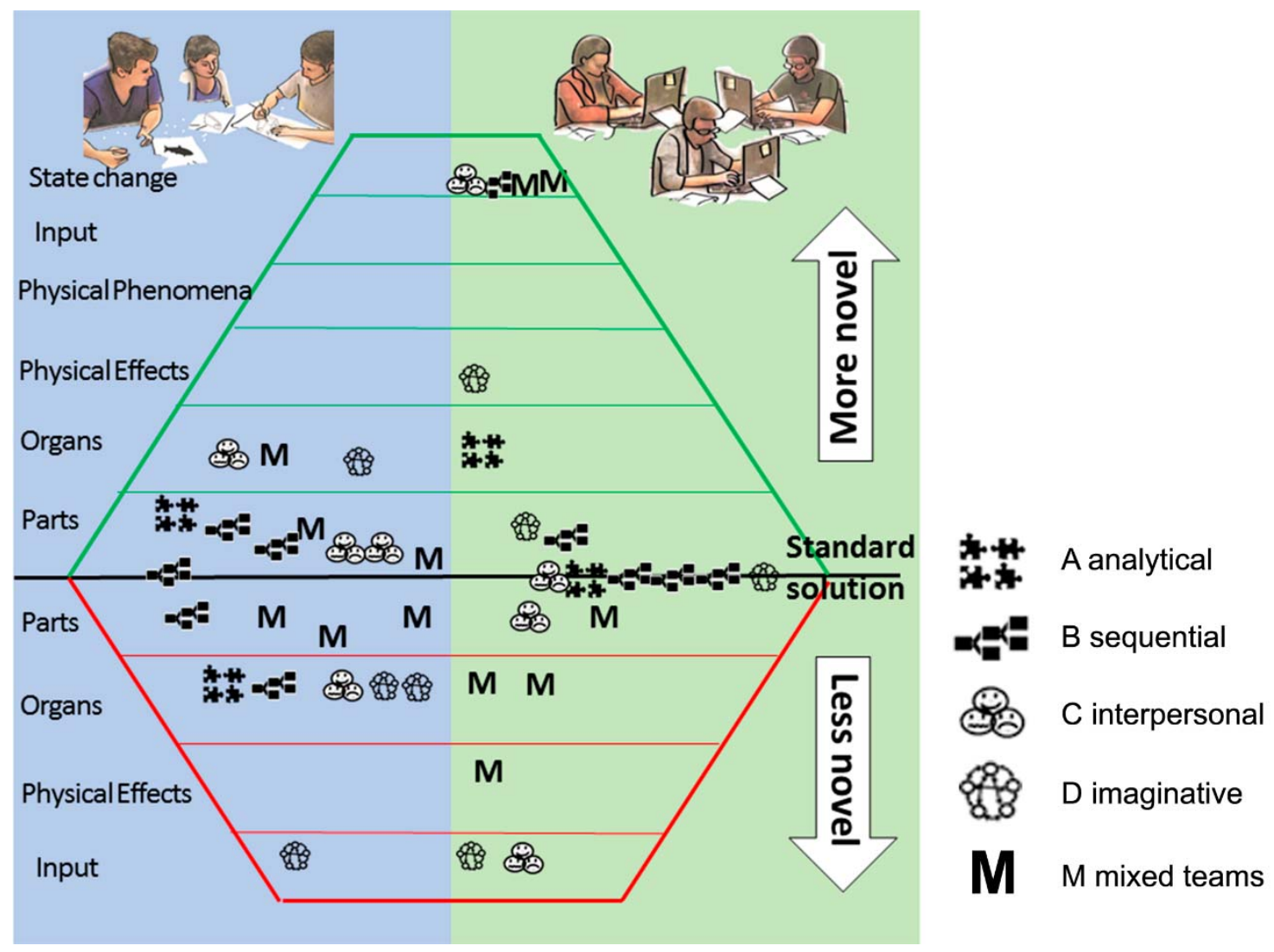

Figure 12. Novelty rank of the design outcomes according to the thinking style

From the point of view of the thinking style, when profile A and B teams are compared, they are seen to be a little more creative with ICT. Thus, these thinking styles (A and B), produce more novel results when they are located in different places and the communication is effected with ICT. Figure 14 shows scatter plot charts with the novelty rank of the design outcomes for each thinking style. As can be seen, all the teams with profile A (analytical) and B (organizational) obtained higher novelty when they used virtual communication than when they worked face-to-face.

Interpersonal teams are, on average, better in face-to-face environments, as could be expected, since personal communication is a prominent feature of this thinking style. One of the most novel solutions of this profile was obtained in the ICT environment. However, three of them present better values with a face-to-face environment. In any case, the team that produced the most novel outcome in a virtual environment also ranks well in terms of novelty in the face-to-face environment. 
Furthermore, profile $\mathrm{C}$ has better results in face-to-face teams than the other profiles. Hence, there seems to be a relation between the thinking style and the working environment, since interpersonal teams ( $\mathrm{C}$ dominance) produce more novel solutions when they can participate in direct face-to-face interaction.

Imaginative teams do a little better in the virtual environment. Most of these teams achieved more novel results working with ICT, although the results show more dispersion. This can be seen in the fact that the most and the least novel outcomes were obtained in the face-to-face environment, indeed the second most novel outcome and one of the least novel of all belong to this profile.

The biggest dispersion is observed when different profiles are mixed in the same team. Three of the six mixed groups were more novel in the virtual environment, two teams were better in the face-to-face environment and the other group was equally novel in both cases. Thus, mixed groups do not seem to be influenced by the environment on average, although with ICT they generate the most and the least novel solutions, whereas in the face-to-face condition the solutions obtained are more similar to the SS.

As can be seen in Figure 13, the median of the novelty rank, located at the change of colour in the box plot, shows that the most novel teams are analyticals (A), followed by sequentials (B), interpersonals (C), imaginatives (D) and mixed teams (M). Nonetheless, distributions show that there is high dispersion, especially in the teams with profiles C, D and mixed. In the face-to-face environment, interpersonal teams (C) are clearly the most novel with low dispersion. Mixed teams increase their novelty a little and profiles A, B and D decrease their novelty in the face-to-face environment in comparison to the overall data. In a virtual environment, profiles A, B and D increase their novelty whereas in interpersonal (C) and mixed (M) teams it decreases. 

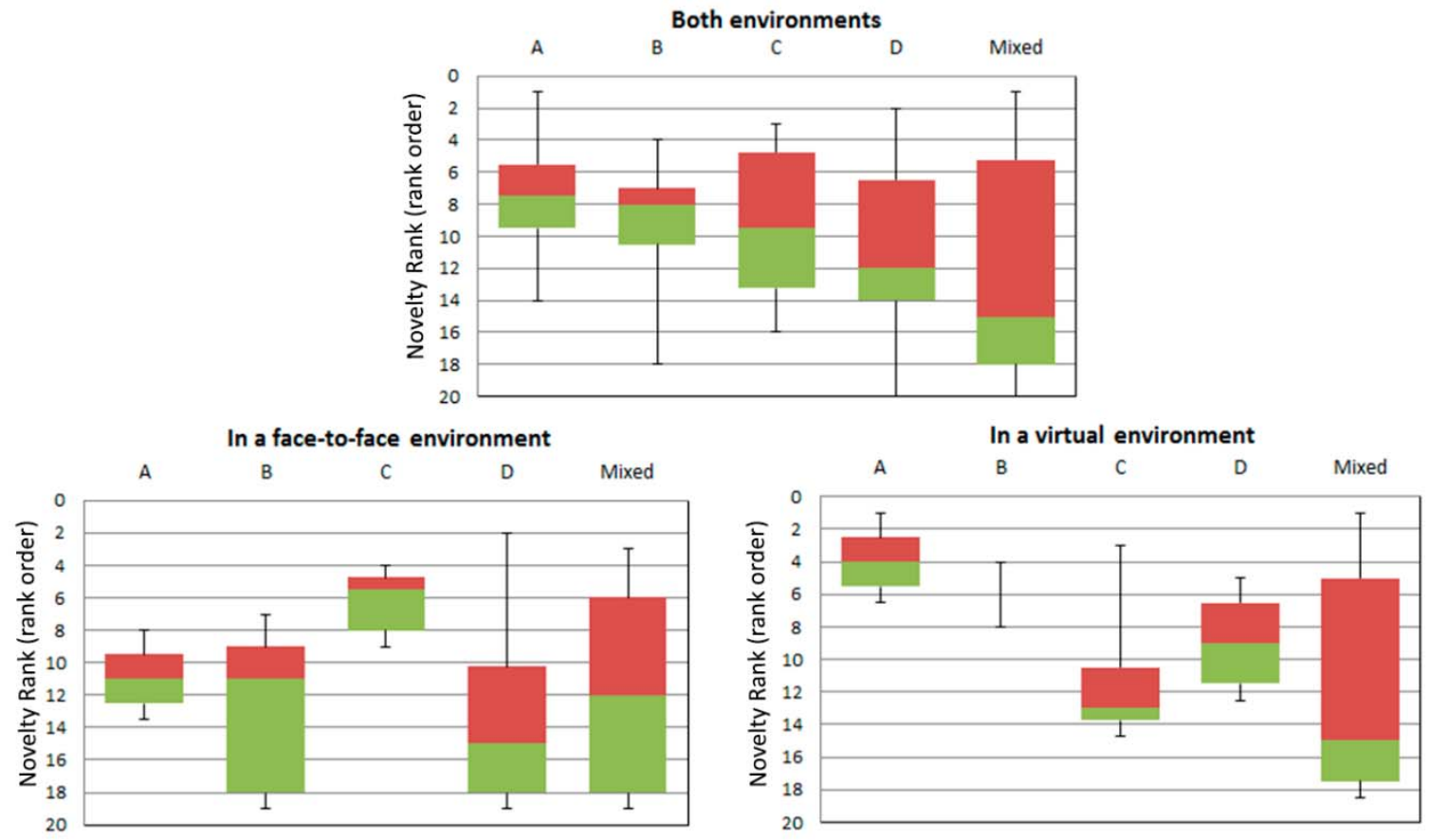

Figure 13. Box plot of the novelty rank according to the dominant thinking style of the teams

The scatter plot charts (Figure 14) show the results for each design team separately. The two teams with profile A improve their novelty when they use technologies. The same happens with sequential teams (B): the five teams improve their novelty in a virtual environment, but in this case the difference is not as high as in the analytical teams. Two of the four interpersonal teams are far more novel in a face-toface environment, whereas the other two are similar in both environments although slightly more novel in the virtual environment. Three of the four imaginative teams are more novel using technologies to communicate with each other during the creative process and finally, in the mixed groups, the data are very dispersed and the type of environment does not seem to have any kind of influence on this team profile. 


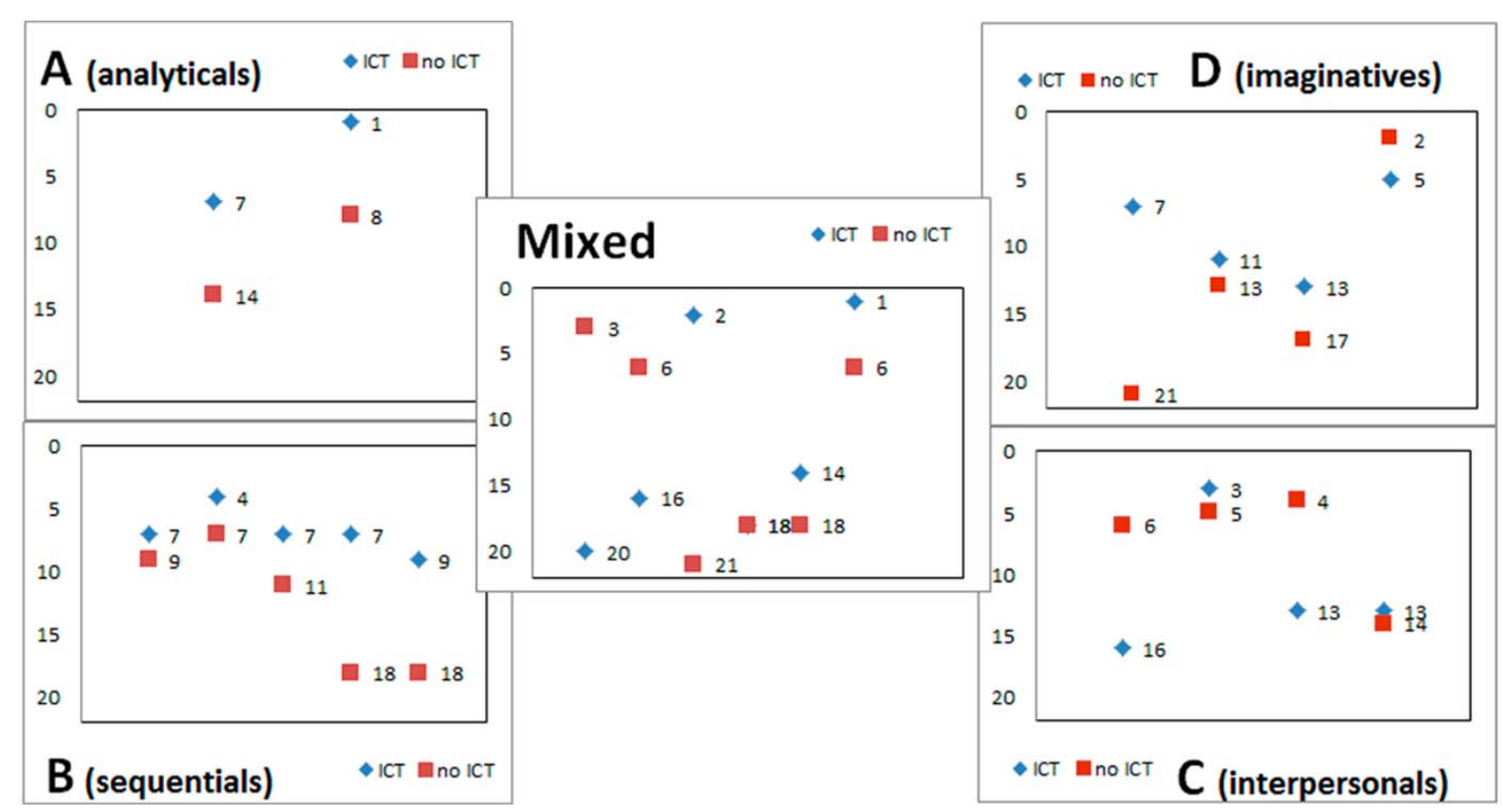

Figure 14. Scatter plot charts of the novelty rank for each thinking style

With the available results it is not possible to determine statistically the interaction between the thinking style and the environment in terms of the level of novelty of the design outcomes. In sum, these preliminary qualitative findings are obtained for each thinking style:

- Analytical teams (A) seem to produce the most novel results in the virtual environment.

- It is observed that sequential teams (B) have the less dispersion in novelty. With the data available they are in second place in the virtual environment, but in the face-to-face situation the dispersion is high.

- In this experiment, interpersonal teams (C) provide the most novel solutions in the face-to-face environment with a low dispersion, as shown in Figure 13. In the virtual environment the novelty of their results decreases significantly. 
- Imaginative teams (D) have the less novel solutions in the face-to-face environment, although it improves quite a lot in the virtual one. The relationship between this style and the novelty rank is inconclusive.

- Mixed teams have the most varied novelty rank results, as can be seen in Figure 13. With the data from this experiment, this is the least novel style in the virtual environment.

- With the available results, shown in Figures 12, 13 and 14, it is observed that the novelty results of the interpersonal (C) and the analytical teams (A) are the most dependent on the working environment in comparison to the other thinking styles.

As a conclusion, it can be said that with the data collected, the dominant thinking style of a design team does seem to influence the degree of novelty of the design outcomes. This influence seems to depend on the kind of environment: virtual or face-to-face, especially for interpersonal and analytical thinking styles.

A possible reason why analytical teams are more novel in the virtual environment is that the lack of visual communication with the other team members made them feel freer, more comfortable and uninhibited to propose novel ideas than in the face-to-face environment. This could be due to the fact that communication preferences of analytical people are based on precise and accurate data and a straightforward style. Hence, the virtual environment providing a chat and a sharable sketching area seems well-suited to analytical teams.

Conversely, for interpersonal teams, the face-to-face environment allows gestures, open discussions and perception of voice tone and facial expressions. All these features coincide with interpersonal communication preferences and could be the reason why they have been more novel in the face-to-face environment. 


\section{Limitations and comparison with other studies}

Although the novelty is, overall, a little higher when ICT are employed, there are no significant differences from the statistical point of view. It therefore seems that a design team can work together to generate creative solutions by means of either face-to-face or virtual communication. In this experiment the virtual environment did not allow audiovisual communication, only chat capabilities and the sharable drawing application were available. Even though initially the absence of audio communication was expected to be a disadvantage, it did not lead to less novel results. One reason for this could be that, unlike the face-to-face environment, the designers used the chat application almost exclusively to contribute to the assigned task, thus reducing the number of conversations that were not related to the design problem. Another reason could be that the lack of physical presence of the rest of the team members could lead to a higher level of concentration on the design problem, which to a certain extent offset the communication limitations.

When the results are compared in relation to the thinking style, it is observed that profiles A and B produce more novel results in the virtual environment, whereas teams with profile $\mathrm{C}$, characterized by interpersonal interactions, are more novel in face-to-face communication.

Mixed teams produced less novel outcomes, which could be due to the fact that in mixed groups the participants need training or preparation time in order to "establish" an effective communication among them that leads to effective team work. Since none of the groups had any preparation time to understand how they worked as a team, maybe the mixed teams started being creative and generating creative solutions later 
than the other teams. Since the total time of the experiment is the same for all the teams, this could be a reason explaining why mixed groups are less novel than the others.

In the work by Tang, Lee and Gero (2011), the design outcomes obtained by the teams were scored by six judges who did not know whether the design had been obtained working in a traditional or in a digital environment. The results show that the average score in traditional environments is marginally higher than in digital environments, yet half of the teams had better scores in the digital environment than in the traditional one. In the present study only the degree of novelty, according to the SAPPhIRE model, was measured to compare the design outcomes, whereas in the work by Tang et al. six evaluation criteria were considered and scored according to the judges' opinion. Even though the distributed environment setting and the outcome evaluation are different, it is interesting that neither of the studies provide any significant differences in the two working environments.

In the experiment reported here, communication through gestures was not available for the teams that used information and communication technologies. It is relevant how the absence of this communication modality does not influence the level of novelty of the results, since gestures, together with talking and sketching, play a role in the co-creation of ideas (Tholander et al. 2008). A recent study comparing verbal, sketching and gesture communication between co-located and distributed teams showed that, even though all the interaction modes were available in the distributed conditions, the time dedicated to gestures decreased and the sketching activity increased in the distributed conditions in comparison to the co-located ones. This could be due to the fact that gestures were more restricted in the distributed conditions and designers compensated for it in some way (Eris, Martelaro and Badke-Schaub 2014). In the experiment presented in this paper, a compensatory communication interaction perhaps 
occurred during the creative design process that could be a subject of study for future works.

It is also interesting to remark that the students who participated in this experiment knew each other and had developed trust. Several studies have shown that when trust has been developed, virtual tasks are easier to do (Jarvenpaa, Knoll and Leidner 1998), so the results could be different without this level of trust and the findings are limited to teams with previously developed trust.

The two design problems are similar in level of complexity and level of innovation required. The total time available to perform the task and other variables related with the nature of the design problems could be analysed in future studies. At the end of the experiment, the participants expressed a different level of motivation for each of the two design problems and the degree of novelty of the outcomes was also different. Further studies should take this variable into account by means of a systematic analysis of the designers' experience with the problem as users and how important it is for them.

This work shows how the environment produces no significant differences in the level of novelty of the design outcome. The results provide preliminary support to the hypothesis that the communication channels available for design teams affect them in different ways, depending on the teams' thinking style. Hence, in further research it could be interesting to study whether teams with an interpersonal profile provide more novel solutions in a virtual environment if the verbal and gestural communication modes are allowed.

\section{Conclusions}

As conclusions, the degree of novelty measured in this experiment is quite similar in both environments, although it is a little more novel when ICT are employed, but no 
statistically significant differences are found. Moreover, using ICT leads to more differences between the novelty of the standard solution and the novelty of the solutions obtained than when no ICT environment is used. The degree of motivation also changes with the problem, the fingernail painter being more interesting for them since most of the participants had some previous experience with it, which has influenced the result. The dispersion of the novelty is also different between the two problems as, for example, in the fingernail painter the top five novel solutions were obtained using ICT and for the fishbone device all the solutions are more similar to each other in the degree of novelty, as well as being more similar to the standard solution.

From the thinking style point of view, it is not possible to determine a quantitative conclusion, since the number of groups for each profile is different and low. In any case, preliminary results show that there can be an influence of the interaction between the environment and the thinking style, since the rational profiles A and B produce more novel results when using ICT than in a face-to-face environment; and profile C (interpersonal) teams generate the least novel solutions when using technologies and produce the most novel solutions when they work in a face-to-face environment. Hence, there seems to be a relationship between the communication environment and the thinking style, and this dependence seems to be stronger in the interpersonal (C) and analytical (A) styles. As could be expected, the profile associated with interpersonal relationships yields better results working in a team within a face-toface environment. In contrast, the most rational profiles seem to work a little better in an ICT environment.

Imaginative teams (D) were not the most creative groups in this experiment, although they were a little more novel with ICT. Mixed groups produce good and bad results in both environments. In fact these groups were not very creative, maybe 
because of some characteristic of the experiment or perhaps for some other reason lying beyond the scope of this study.

To sum up, to perform a creative design task in teams, distributed teams that need to communicate with each other using a digital environment can also be creative, although there seems to be an interaction between the environment and the thinking style of the group.

This paper confirms the previous finding that the influence of the virtual work environment on the design outcomes is similar to that of the traditional one. This study is a starting point to research the relationships amongst thinking style, novelty rank, and work environments. More data are needed to confirm these preliminary results and provide statistical evidence of the dependence between the thinking style and the work environment.

\section{Acknowledgments}

This work has been carried out thanks to the research project with code P11B2010-51 entitled "Estimulación y evaluación de la creatividad en el diseño de productos en equipos de diseño distribuidos", and funded by Universitat Jaume I.

\section{References}

Alahuhta, P. and M. Vartiainen. 2014. "Artifacts Supporting Distributed Design Collaboration". In Miko Laakso and Ekman, K. eds. NordDESIGN. Espoo, Finland.

Amitani, S., Z. Bilda and E. Edmonds. 2008. "Our content: generative montage methods for multimedia data". Design Studies 29: 572-586.

Berger, K., A. Surovek, D. Jensen and D. Cropley. 2014. " Individual creativity and team engineering design: A taxonomy for team composition". In Frontiers in Education Conference (FIE). IEEE., 1-4.

Besemer, S.P. and K. O'Quin. 1999. "Confirming the three-factor creative product analysis matrix model in an American sample". Creativity Research Journal 12: 287-296.

Bunderson, V. 1980. The validity of the Herrmann Brain Dominance Instrument. Retrieved from: http://www.hbdi.com/uploads/100021resources/100331.pdf

Candy, L. and E. Edmonds. 2000. "Creativity Enhancement with Emerging Technologies". Communications of the ACM 43 (8): 62 - 65.

Chakrabarti, A., P. Sarkar, B. Leelavathamma and B.S. Nataraju. 2005. "A functional representation for aiding biomimetic and artificial inspiration of new ideas". 
Artificial intelligence for engineering design, analysis and manufacturing (AIEDAM) 19: 113-132.

Chulvi, V., F. Felip, C. García, J. Galán and E. Mulet. 2013. "Is there a correlation between the profiles of the students and their choice of specialty?". 17th International Congress on Project Management and Engineering. Logroño, Spain: AEIPRO.

Dayan, M. and C. Di Benedetto. 2011. "Team intuition as a continuum construct and new product creativity: The role of environmental turbulence, team experience, and stress". Research Policy 40 (2): 276-286.

Dorst, K. 2004. "On the problem of design problems - problem solving and design expertise". Journal of Design Research 4 (2)

Dreyfus, H.L. 2003. Unpublished notes from the Spinoza lectures. University of Amsterdam

Eris, O., N. Martelaro and P. Badke-Schaub. 2014. "A comparative analysis of multimodal communication during design sketching in co-located and distributed environments". Design Studies 35 (6): 559-592.

Freiheit, T. 2015. "The Influence of Personality Factors on Design Group Work Outcomes". IIE Annual Conference. Proceedings. Institute of Industrial Engineers, Inc. (IIE). HighBeam Research.

Frost, R.B. 1994. "A Suggested Taxonomy For Engineering Design Problems". Journal of Engineering Design 5 (4)

Gero, J. 1990. "Design prototypes: A knowledge representation schema for design". AI magazine 11 (4): 26 - 36.

Gough, H.G. and A.B. Heilbrun. 1983. The Adjective Check List Manual California: Consulting Psychologists Press.

Guilford, J.P. 1980. "Some changes in the structure of intellect model". Educational and Psychological Measurement 48: 1-4.

Herrmann, N. 1989. Participant survey form of the Herrmann brain dominance instrument. [online]. http://www.thinkingmatters.com/survey.pdf.

Herrmann, N. 1991. "The creative brain". The Journal of Creative Behavior 25 (4): 275295.

Herrmann, N. 1996. The Whole Brain Business Book New York, NY: McGraw-Hill.

Jarvenpaa, S.L., K. Knoll and D.E. Leidner. 1998. "Is Anybody out There? Antecedents of Trust in Global Virtual Teams". Journal of Management Information Systems 14 (4): 29-64.

Jiménez-Vélez, C.A. 2003. Neuropedagogía lúdica y competencias Bogotá: Coop. Editorial Magisterio.

Kim, Y.S., S.T. Jin and S.W. Lee. 2009. "Relations between design activities and personal creativity modes". Journal of Engineering Design 22 (4): 235-257.

Kim, Y.S., M.S. Kim and D.J. Wilde. 2008. "Toward the management of design creativity: Personal creativity modes, design activity, and team interaction". Design Management Journal 3 (2): 45-52.

Kirton, M. 1976. " Adaptors and innovators: A description and measure". Journal of Applied Psychology 61 (5): 622-629.

Kirton, M.J. 1985, 1992, 1999. "Kirton adaption-innovation inventory. Feedback booklet". Berkhamsted, UK: Occupational Research Centre.

Kleinsmann, M., F. Deken, A. Dong and K. Lauche. 2011. "Development of design collaboration skills". Journal of Engineering Design 23 (7): 485-506.

Landis, J.R. and G.G. Koch. 1977. "The measurement of observer agreement for categorical data". Biometrics 33 (1): 159-174. 
Leggte, M. and Z. Bilda. 2008. "Exploring design options for interactive video with the Mnemovie hypervideo system". Design Studies 29: 587-602.

López-Mesa, B., E. Mulet, R. Vidal, M.J. Bellés and G. Thompson. 2005. "Creativity in people vs in methods". 9th International Congress on Project Management and Engineering. Málaga, España.

López-Mesa, B. and G. Thompson. 2006. "On the significance of cognitive style and the selection of appropriate design methods". Journal of Engineering Design 17 (4): 371-386.

MacGregor, S. and T. Torres-Coronas. 2007. Higher creativity for virtual teams: developing platforms for co-creation USA and UK: IGI Global.

MacLean, P.D. and V.A. Kral. 1973. A triune concept of the brain and behaviour Toronto: University of Toronto Press.

Nielsen, J.A., B.A. Zielinski, M.A. Ferguson, J.E. Lainhart and J.S. Anderson. 2013. "An evaluation of the left-brain vs. right-brain hypothesis with resting state functional connectivity magnetic resonance imaging". PLoS One 8 (8)

Peeters, M.A.G., C.G. Rutte, H.F.J.M. van Tuijl and I.M.M.J. Reymen. 2008. "Designing in teams: Does personality matter?". Small Group Research 39 (4): 438-467.

Purcell, A. and J. Gero. 1998. "Drawings and the Design Process". Design Studies 19 (4): $389-430$.

Royo, M., A. López-Meri, D. Monferrer, M. Estrada, M.M. Segarra and E. Mulet. 2014. "Analysis of the dominant mode of thinking of university students in different fields of studies using the four brain model of Hermann". 8th International Technology, Education and Development Conference (INTED). Valencia, Spain.

Sarkar, P. and A. Chakrabarti. 2011. "Assessing design creativity". Design Studies 32 (4): 348-383.

Shah, J. and N. Vargas-Hernández. 2003. "Metrics for measuring ideation effectiveness". Design Studies 24: 111-134.

Simoff, S. and M. Maher. 2000. "Analysing participation in collaborative design environments". Design Studies 21 (2): 119-144.

Sperry, R., M. Gazzaniga and J. Bogen. 1969. "Interhemispheric relationships: The neocortical commissures, syndromes of hemisphere disconnection". Handbook of Clinical Neurology. 4 273-290.

Srinivasan, V. and A. Chakrabarti. 2010. "Investigating novelty-outcome relationships in engineering design". Artificial Intelligence for Engineering Design, Analysis and Manufacturing: AIEDAM 24 (2): 161-178.

Stempfle, J. and P. Badke-Schaub. 2002. "Thinking in design teams-an analysis of team communication". Design Studies 23: 473-496.

Suwa, M., T. Purcell and J. Gero. 1998. "Macroscopic analysis of design processes based on a scheme for coding designers cognitive actions". Design Studies Vol.19: 455-483.

Tang, H.H., Y.Y. Lee and J.S. Gero. 2011. "Comparing collaborative co-located and distributed design processes in digital and traditional sketching environments: A protocol study using the function-behaviour-structure coding scheme". Design Studies 32 (1): 1-29.

Tholander, J., K. Karlgren, R. Ramberg and P. Sökjer. 2008. "Where all the interaction is: sketching in interaction design as an embodied practice". Proceedings of the 7th ACM conference on Designing interactive systems. ACM, 445-454.

Umeda, Y., H. Takeda, T. Tomiyama and H. Yoshikawa. 1990. "Function, behaviour, and structure". In Gero, J. ed. Applications of artificial intelligence in 
engineering $V$. Berlin: Springer, 1 177-194.

Van der Lugt, R. 2000. "Devoloping a graphic tool for creative problem solving in design groups". Design Studies 21 (5): 505-522.

Wilde, D.J. 1999. "Design team role". Proceedings of the ASME International conference on design theory and methodology. Las Vegas, NV.

Yang, M. 2009. "Observations on concept generation and sketching in engineering design". Research in Engineering Design 20 (1): 1-11.

Yang, X., A. Dong and M. Helander. 2011. "The analysis of knowledge integration in collaborative engineering teams". Journal of Engineering Design 23 (2): 119133. 